\title{
Tweeting after an earthquake: user localization and communication patterns during the 2012 Emilia seismic sequence
}

\author{
Francesca Comunello ${ }^{1, \star}$, Lorenza Parisi ${ }^{2}$, Valentino Lauciani ${ }^{3}$, \\ Federica Magnoni ${ }^{3}$, Emanuele Casarotti ${ }^{3}$ \\ ${ }^{1}$ Università di Roma LUMSA, Rome, Italy \\ ${ }^{2}$ John Cabot University, Department of Communication, Rome, Italy \\ ${ }^{3}$ Istituto Nazionale di Geofisica e Vulcanologia, Rome, Italy
}

\author{
Article history \\ Received December 28, 2015; accepted July 8, 2016. \\ Subject classification: \\ Earthquake perception, Social media, Disaster communication, Twitter.
}

\begin{abstract}
The main goal of this paper is analysing how user's location, relative to the epicenter of an earthquake, affects the different tweeting strategies adopted. For this purpose, we analyze a dataset of tweets that were generated around the 2012 Emilia earthquakes and that are geolocalized in Italy. In our analysis, we rely on existing literature on social media and natural disasters, considering literature exploring interactions and influence on Twitter, and literature focusing on the role of geolocalized usergenerated information in disaster response.
\end{abstract}

\section{Background:}

disaster communication and social media

Literature on disaster research [Rodriguez et al. 2007], and on emergency and crisis communication [Coombs and Holladay 2010], has a long and established tradition, while research on the role of social media during disasters has been defined as "a largely untapped site of study" [Potts 2013, p. 98]. Only in recent years have social media scholars started devoting their attention to the role of social network sites (SNS) during natural disasters, analysing different contexts and social media platforms, and adopting both a top-down perspective, focusing on institutional communication and emergency management processes [Hughes et al. 2014a, Giacobe and Soule 2014], or on the role of nonprofit and media organizations [Mularidharan et al. 2011]; and a bottom-up perspective (focusing on emergent communication practices and on self-organizing processes; e.g. White et al. [2014]).

In similar contexts, institutions need to find their way to become influential, in order to spread useful and verified information and to limit the circulation of false rumors, as well as to integrate social media in their broader emergency management and communication processes. In this regard, Hughes et al. [2014b] provide an extensive review of literature analyzing the role of social media in emergency management, considering the early stages of social media usage by institutional early adopters, as well as the current usage of social media in formal emergency management. Among the main challenges to social media adoption by emergency managers, the Authors include changes in role and responsibility; concerns with liability; deluge of data; trustworthiness of citizen-generated data; reliability of social media networks; and information overload. Furthermore, focusing on social media adoption by local level emergency managers in the USA, Plotnick et al. [2015] identify the main barriers to social media usage for sending out and gathering information, which include the lack of staff (quantity), the lack of formal social media policies, the lack of staff (skills) and experience with social media, the trustworthiness of public generated content, underlining that countylevel agencies "are not yet ready to embrace SM and use it to its fullest potential” [p. 10].

Considering bottom-up communication, on the other hand, while individual motivations for social media usage in the aftermath of natural disasters did not receive broad attention by scholars, Fraustino et al. [2012] identified different motivations that can be summarized into these three macro categories: information seeking and sharing, communicating with personal networks, finding emotional support. Such bottom-up activities can play a relevant role in disaster response, as users can be involved both as (social media) volunteers, for spreading verified information, for the detection of 
the needs of local communities and individuals, and as a source for early detection of events.

For instance, Potts [2013] argued that social media provide "people-powered, decentralized communication systems [that] could eventually become effective during times of disaster", in order to "organize missing-persons lists, coordinate relief supplies, and exchange news about the situation" [p. 40], thus highlighting the potentials of integrating users' interactions in broader disaster response processes. Starbird and Palen [2011], for instance, focused on the forms of volunteering enabled by social media, analyzing the role of so-called voluntweeters, users that were actively engaged in contributing to gathering and processing meaningful information in the aftermath of the Haiti earthquake. Cooper et al. [2015] go further in this direction, by proposing several criteria institutional emergency respondents could adopt in order to select and recruit "social media savy" users, and involve them in emergency response processes on a local basis, highlighting the relevance of each users' (social media) relational network, as well as their skills in using social media platforms' features.

Earle et al. [2010], as well as Avvenuti et al. [2016], on the other hand, explore another relevant application of bottom-up communication processes during natural disasters, investigating the potentials of user-generated information for the early detection of natural events, and considering the role of Humans as a Sensor.

When analyzing how Twitter is used in the aftermath of natural disasters, scholars have focused on several dimensions, including Twitter basic metrics, tweet distribution over time, information spread and the role of so-called influencers. Less attention has been devoted to qualitative analyses and tweet categorization, in order to grasp the nuances of tweet content. With regard to Twitter metrics, during emergencies users are more likely to include URLs (links) in their tweets [Starbid and Palen 2010, Bruns et al. 2012, Bruns and Stieglitz 2014], and to share multimedia content [Bruns et al. 2012, p. 33-36]. Comparing basic Twitter metrics in different datasets, Bruns and Stieglitz [2014, p. 80] show that tweets related to natural disasters are more likely to contain URLs and retweets (RT): in the aftermath of natural disasters, users find and share information in order to achieve a process of "collaborative curation of information" [Bruns and Stieglitz 2014, p. 26]; the retweet ratio is even higher after events that cannot be foreseen, like earthquakes: in such cases, retweets are used in order to "raise awareness". Only in subsequent stages a major role is played by reactions and discussion, including tweets related to offers of help and fundraising activities [Bruns et al. 2012].
Another important topic, when analysing the role of social media during natural disasters, is information spread and the related role of so-called influencers, a broad and fuzzy category that includes different types of users, ranging from Twitter celebrities to off-line celebrities [Marwick and Boyd 2011], to users showing expertise on specific topics, to even "common users" who appear, from time to time, to be able to exert a significant influence over other users. More specifically, "most influential users hold significant influence over a variety of topics," while ordinary users "can gain influence by focusing on a single topic and posting creative and insightful tweets that are perceived as valuable by others" [Cha et. al. 2010, p. 11]. Interactions and influence on Twitter can be related to three structural layers of communication: the micro level (conversations between single users, @reply), the meso level (follower-followee networks), and the macro level (hashtag conversations) [Bruns and Moe 2014].

While providing rich insights into disaster-related social media activities, for instance, such analyses generally fail to consider the geographic dimension related to user activities, mainly focusing on specific hashtag or keywords in order to gather (and analyze) the tweets. On the other hand, with few relevant exceptions (see, for instance, Taylor et al. [2014], Cooper et al. [2015]) literature considering the distribution of geolocalized tweets often fails to provide in-depth analyses of tweet content and of influence dynamics on the platform. Nevertheless, geolocalized tweets play a relevant role in literature focusing on disaster prediction (see Earle et al. [2010], MacEachren et al. [2011], Wilken [2014]), or on the role of Twitter in supporting crisis management [Cooper et al. 2015]. In this regard, Avvenuti et al. [2016], for instance, report the possibility of using geolocalized tweets for detecting earthquakes with timing even comparable to the seismic networks [i.e. Avvenuti et al. 2016].

We are convinced that analyzing Twitter activities in relation to user location is crucial for better interpreting the role and the relevance of their tweets, as user-generated geographic information "reflects the lived experiences of the people creating it" [Taylor et al. 2014, p. 167]. Therefore, in this paper we explore the ways in which user location affects their tweeting strategies (considering twitter metrics, patterns of influence, tweet content).

\section{Tweeting after an earthquake: our research project}

In May-June 2012 a major seismic activity occurred in Emilia, northern Italy. The principal events of the sequence were a $M_{L} 5.9$ and a $M_{L}$ 5.8. 27 people were killed and more than 350 injured; moreover, several historical buildings, factories and houses were damaged. 
The 2012 seismic sequence in Emilia is one of the first natural disasters in Italy that has been largely commented on Twitter, and \#terremoto ("earthquake" in Italian) has been a long-lasting Italian trending topic on the platform. In this paper we present the results of an analysis of the dataset of the geolocalized tweets containing the words "terremoto" and/or "earthquake" that can be related to the May-June 2012 earthquakes in Emilia Region.

The following results are a part of broader research project ShakeNetworks (Italian PRIN 2012) that adopts a multidisciplinary approach, integrating a sociological and communication perspective (with a main focus on internet studies) with insights from geophysics (with regard to seismological parameters and to citizen-generated information about the earthquake effects).

In this paper, we have decided to focus only on a specific platform: Twitter. Among our motivations for such a choice are: the large amount of disaster-related conversations taking place on Twitter during and after acute events; the prevalence of public accounts among Twitter users $(97.7 \%$ of the last 100 million accounts at May 2012; http:/ / www.twopblog.com/2012/05/last100-million-twitter-accounts.html); the role of some specific Twitter features, such as the retweet feature; and the public dimension of hashtag conversations.

\subsection{Research goals and method}

Our main research goal is to understand how user's location, more precisely, the distance from the zone where the perceived effects of the earthquake are more intense, is related to different Twitter usage strategies.

Contrary to other natural disasters (e.g. floods), in the Italian language an earthquake is an event that can be univocally identified by using the word "terremoto": the majority of Twitter users made use of that single word to comment the ongoing event, even if no official hashtag had been adopted by authorities.

As shown in Table 1, the main shakes of the sequence occurred on May 20 (02:03:52 UTC) and on May 29 (07:00:03 UTC), and other five shakes exceeded $M_{L} 5$.

The dataset includes 12,779 tweets that:

- contain words such as "terremoto" or "earthquake"; - were written between May 20 and June 4, 2012; - are geolocalized in Italy.

All tweets have been extracted in real time using the Twitter Streaming API, which is "likely the most widely used data source for Twitter research" [Gaffney and Pushmann 2014, p. 56]. As Gaffney and Pushmann point out, while non-Firehose access only delivers a limited percentage of "all tweets posted on the system [...], the percentage caps come into effect only when more

\begin{tabular}{cccc}
$\begin{array}{c}\text { Date } \\
(\mathrm{dd} / \mathrm{mm} / \mathrm{yy})\end{array}$ & $\begin{array}{c}\text { Time } \\
(\mathrm{UTC})\end{array}$ & $\begin{array}{c}\text { Time } \\
(\text { local })\end{array}$ & Magnitude \\
\hline $20 / 05 / 12$ & $02: 03: 52$ & $(04: 03: 52)$ & 5.9 \\
\hline $20 / 05 / 12$ & $02: 07: 31$ & $(04: 07: 31)$ & 5.1 \\
\hline $20 / 05 / 12$ & $13: 18: 02$ & $(15: 18: 02)$ & 5.1 \\
\hline $29 / 05 / 12$ & $07: 00: 03$ & $(09: 00: 03)$ & 5.8 \\
\hline $29 / 05 / 12$ & $10: 55: 57$ & $(12: 55: 57)$ & 5.3 \\
\hline $29 / 05 / 12$ & $11: 00: 25$ & $(13: 00: 25)$ & 5.2 \\
\hline $03 / 06 / 12$ & $19: 20: 43$ & $(21: 20: 43)$ & 5.1 \\
\hline
\end{tabular}

Table 1. The May-June 2012 seismic sequence in Emilia, Italy.

than the respective percentage $[1 \% ; 10 \%]$ of all tweets match the conditions placed on the stream" [2014, pp. 57-58]. This is not the case for tweets containing our keywords and that are geolocalized in Italy, since they are a small part of the whole database. For a comparison between different methods for accessing Twitter datasets, see Morstatter et al. [2013].

Geolocalized tweets are tweets that contain exact information about user's latitude and longitude (users need to enable the geolocalization function on their mobile devices). According to Leetaru et al. [2013], around $2 \%$ of the worldwide tweets contain geographical metadata. Nevertheless, for the scope of this analysis, we believe that user's localization is a key element for understanding communication processes taking place in relation to earthquakes. While an exact estimate of the number of tweets matching all our parameters cannot be done according to GNIP syntax, a rough estimate through the Sifter service (http: / / sifter.texifter. com) confirms that the number of tweets in our dataset is comparable to the whole dataset of the tweets matching our criteria provided through GNIP Power Track (Firehose access). Moreover, such estimates show that the geolocalized tweets are about $2.4 \%$ of all the tweets matching our criteria.

To conduct our analysis, we have labeled three different zones. The first is the "red" zone, where the experienced intensity was highest. It is the zone between the Italian cities Mantova (north) - Bologna (south) - and Reggio Emilia (west). The second is the "green" zone, where the earthquake was experienced, but with less intensity. This zone includes Milan. The third zone is the "white" zone, where the earthquake was not directly experienced. This zone includes the rest of Italy (Figure 1).

The zones were chosen by referring to the macroseismic intensity map (Figure 2) created by Istituto Nazionale di Geofisica e Vulcanologia (INGV) through the online survey www.haisentitoilterremoto.it $(12,926$ citizens answered the survey referring to the May 20 


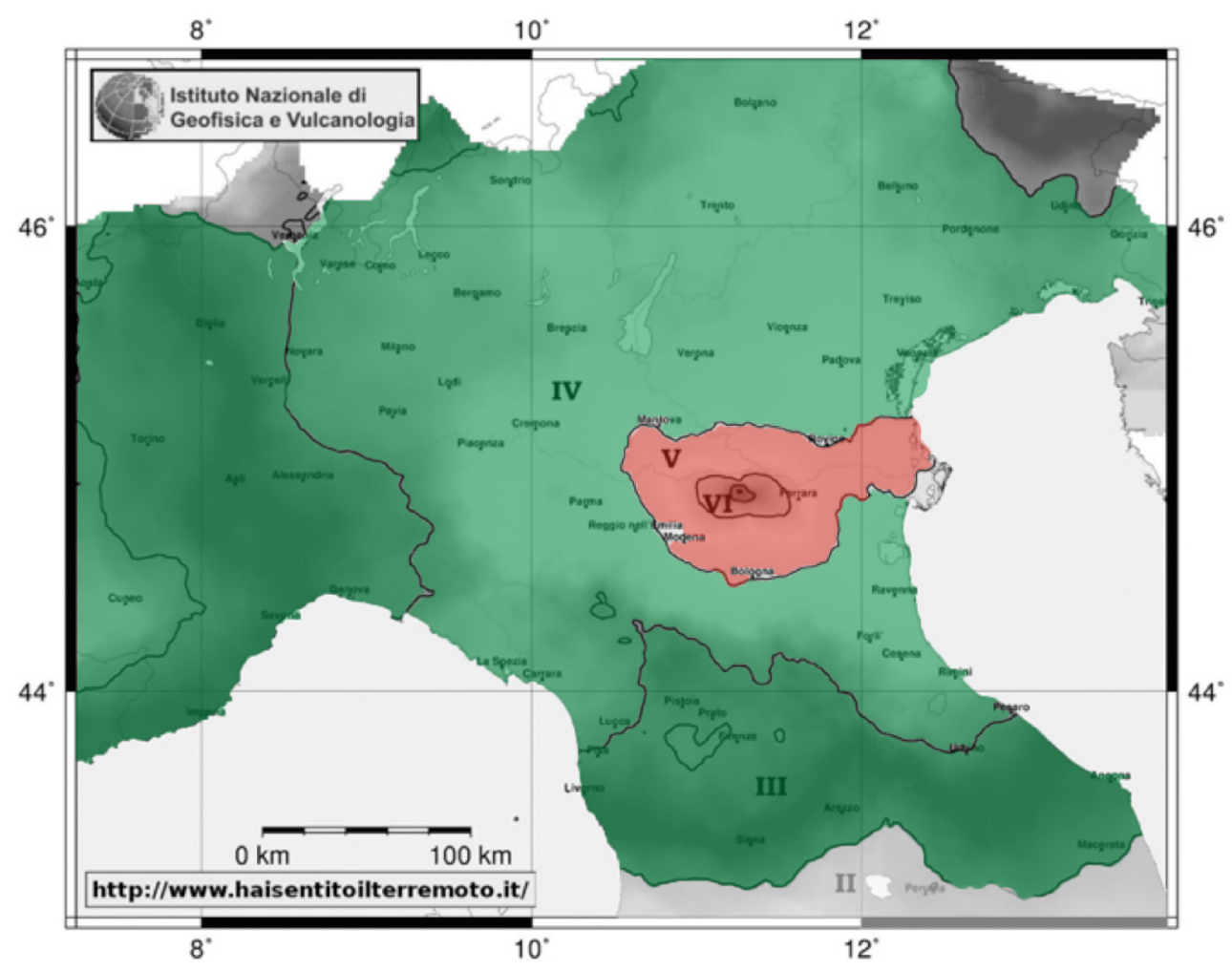

Figure 1. A detail of the map showing the red, green, and white zones.

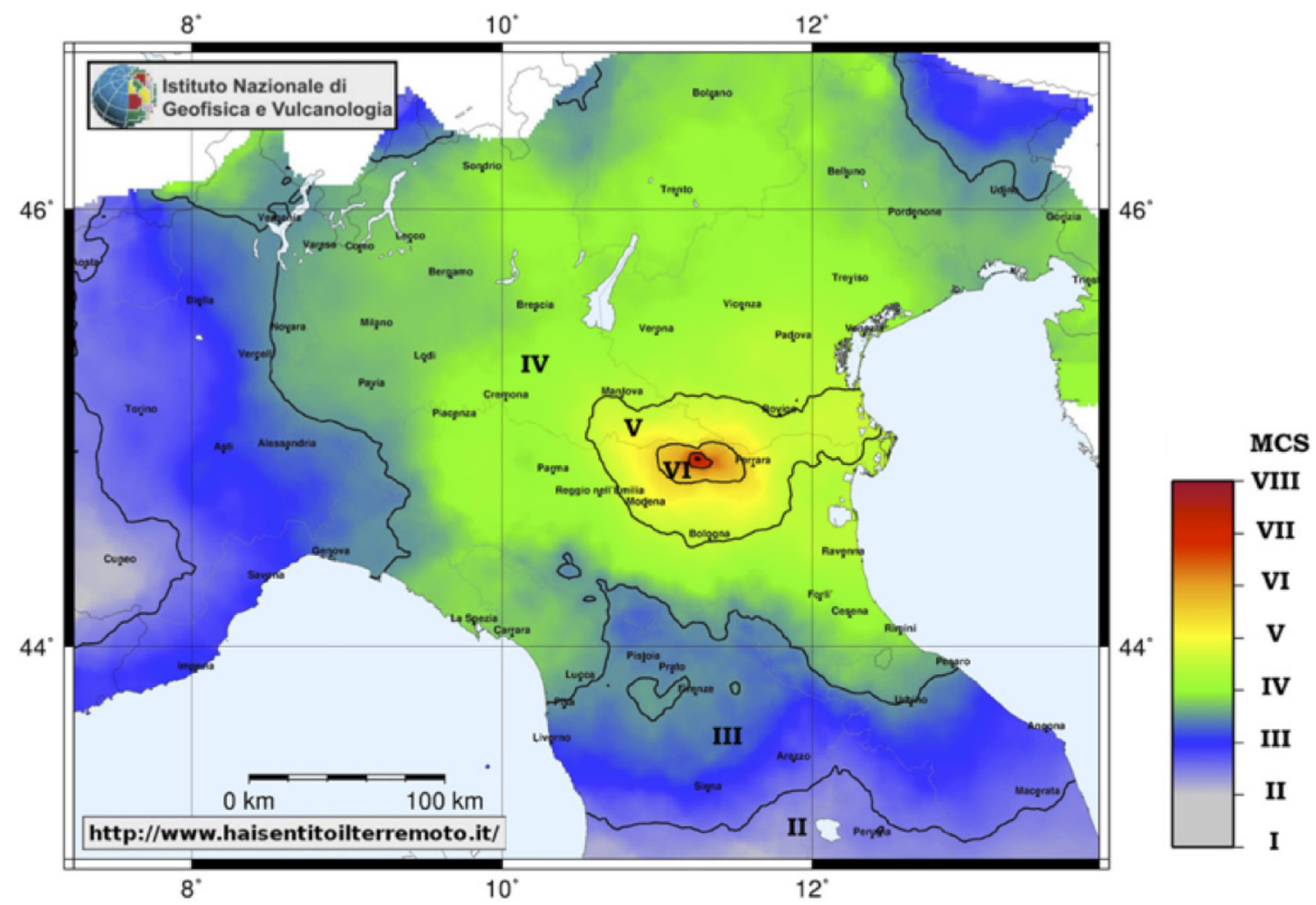

Figure 2. Macroseismic intensity map created by INGV through the online survey www.haisentitoilterremoto.it and referring to the 02:03:52 a.m. UTC earthquake on May 20, 2012. Source: INGV.

shake). The method is described in Tosi et al. [2015]. For gathering preliminary but almost instantly information about what people experienced and the extent of the damage, the adoption of online survey is a standard practice of the principal seismological institutions as USGS (http:/ / earthquake.usgs.gov/ data/dyfi/index.php) or EMSC (http:/ / www.emsc-csem.org/Earthquake/Con tribute/choose_earthquake.php?lang=it) and it represents one of the most robust example of citizen science. We have chosen to map different steps of the Mer- 
calli Cancani Sieberg intensity scale in a single zone. The red zone includes degree $\mathrm{V}$ and over; the green zone includes degrees III and IV. The white zone covers degrees I and II.

2.2. "Quasi real-time communication": tweet distribution over time

Our dataset refers to a two-week period (May 20 June 4, 2012), but Twitter activity is not equally distributed over time, nor among the three zones (see Table 2). As Figures 3 and 4 illustrate, the peaks are clearly identifiable within an hour after a major shake.

\begin{tabular}{lcc} 
& Frequency & Percentage (\%) \\
\hline Total number of tweets & 12779 & \\
\hline Tweets on May 20 & 4225 & 33.1 \\
\hline Tweets on May 29 & 4454 & 34.9 \\
\hline Tweets "red" zone & 4227 & 33.1 \\
\hline Tweets "green" zone & 6885 & 53.9 \\
\hline Tweets "white" zone & 1667 & 13.0 \\
\hline
\end{tabular}

Table 2. Tweets written during the May-June 2012 seismic sequence in Emilia according to users locations (red, green and white zones).

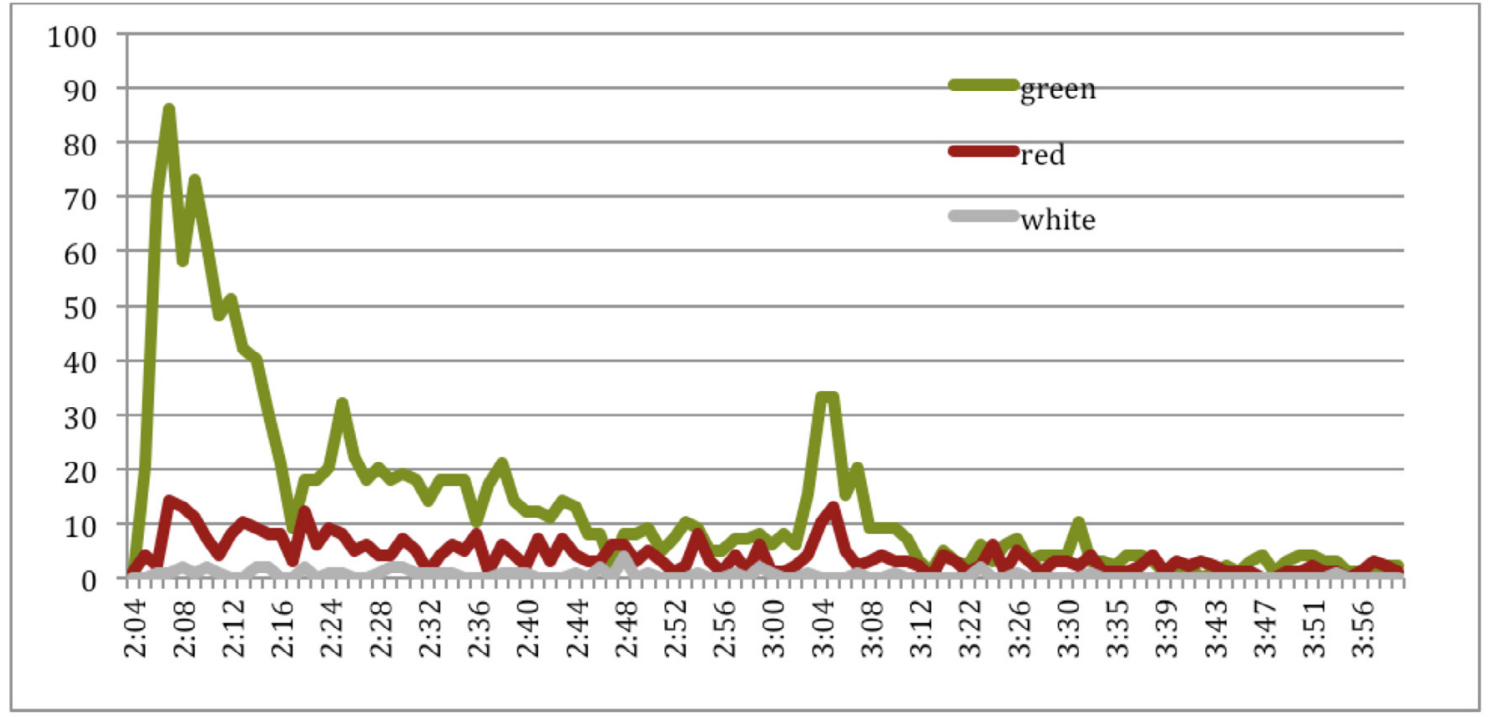

Figure 3. Tweets written after the May 20, 2012, seismic shake (2:03 a.m. - 4:02 a.m. UTC) according to users' locations (green, red and white zones of Figure 1).

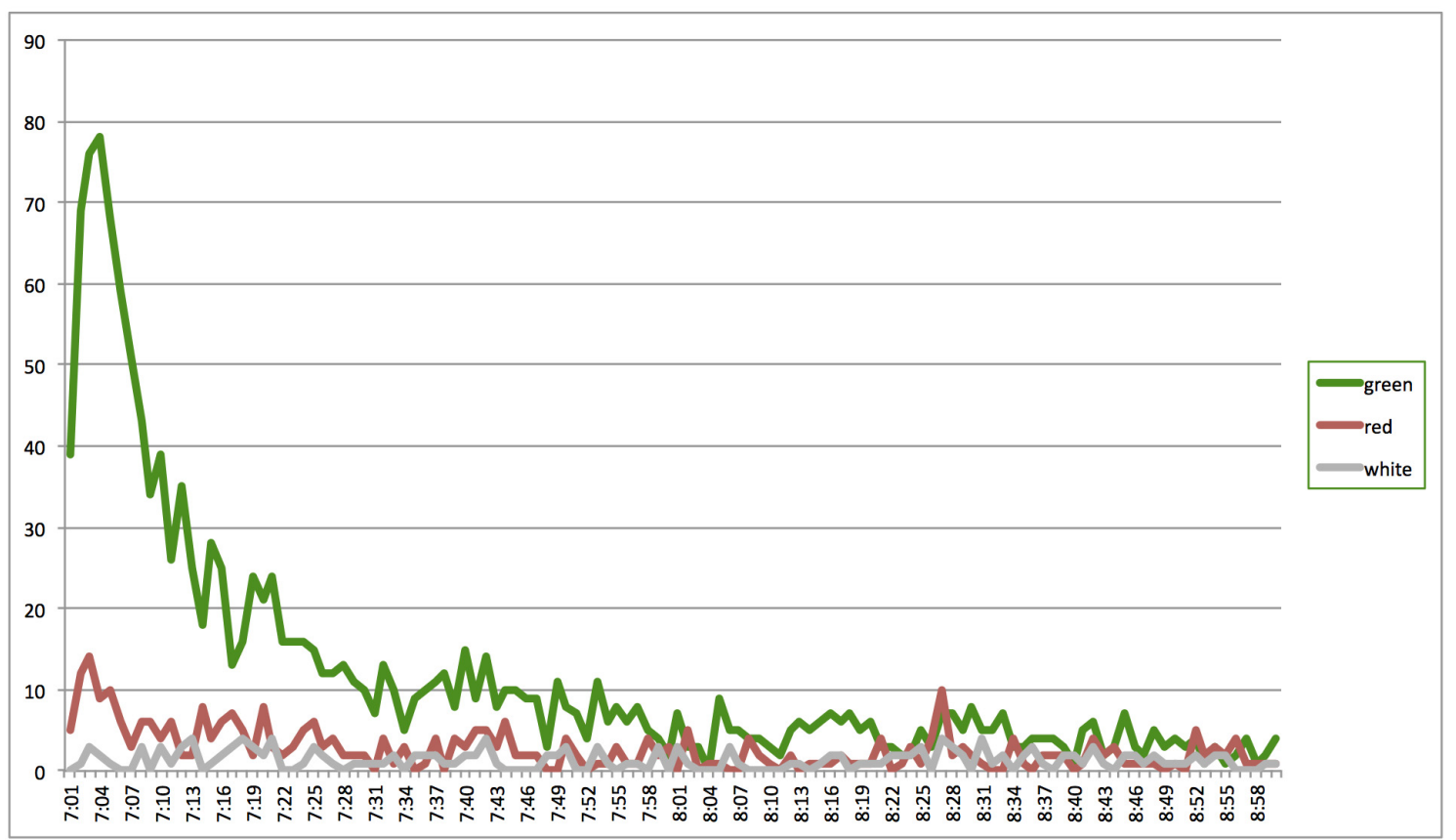

Figure 4. Tweets written after the May 29, 2012, seismic shake (7:00 a.m. - 8:59 a.m. UTC) according to users' locations (green, red and white zones of Figure 1). 
This is the case even if the shake happens during the night. The first geolocalized tweet was written in the red zone (near Bologna) at 2:04:34 UTC (less than a minute after the first shake); it only says "TERREMOTO" ("EARTHQUAKE").

The data confirms Twitter's prevailing orientation towards real-time and "quasi real-time" communication. This is the case for earthquake related communication: it is used for communicating immediately after having felt the shake (or having had the news through the web or the media). Even during a long seismic sequence, Twitter activity related to earthquakes in days with no perceptible seismic activity is very scarce. Nevertheless, we should add that "real-time" tweets may be over-represented in our database given that the geolocalization feature is mainly associated with mobile devices use.

Some differences among the three zones emerge (Figure 5). First of all, we notice an uneven distribution of tweets among the three zones: a majority of tweets (6885) is produced in the green zone, followed by the red zone (4227), while only 1667 tweets are produced in the white zone. This is particularly noteworthy as the red zone is the smallest one, in terms of inhabitants; moreover, Twitter users in Italy are concentrated in major cities, such as Milan (green zone, 1,337,155 inhabitants); Bologna (red zone, 386,181 inhabitants) and Rome (white zone, 2,872,021 inhabitants) [ISTAT 2015].

While the majority of tweets in our database is produced shortly after a major shake, when considering tweet distribution within a single zone (Figure 6), other differences emerge. Within the white zone, for instance, a higher tweet production peak occurred after the May 29 shake (which occurred in daytime, and which had raised a higher public attention since there was a pre-existing media coverage); after the May 20 shake, a relative Twitter peak occurred in the white zone hours later than

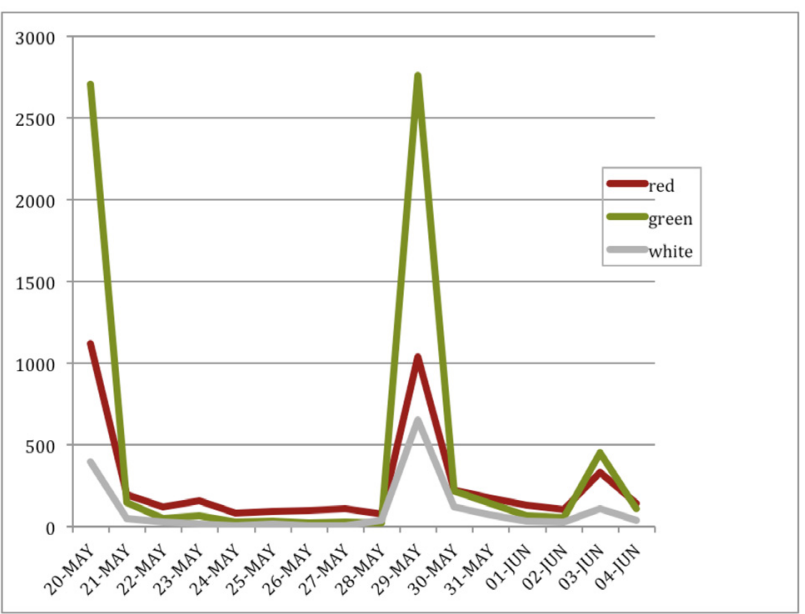

Figure 5. Number of tweets over time (whole database, in the 3 zones of Figure 1). the shake, at the time when people normally wake up.

The highest concentration of tweets immediately after major shakes happened in the green zone. It occurred both after the May 20 shake and after the May 29 shake. Tweets in the first two hours after the shake account for $51.7 \%$ of the tweets of the entire day (Figures 3 and 4). Also in the red zone peaks occurred immediately after the major shakes, but tweets are less concentrated than in the green zone; moreover, the red zone shows more tweet distribution throughout the entire period (see Figures 3 and 4).

\subsection{Common users and Twitter celebrities: basic met-} rics and influence dynamics

We analysed the number of tweets produced by each user in our database in order to identify the most active accounts. The most active Twitter user is surely @INGVterremoti. This is INGV's experimental Twitter account that has been created to report almost in real time Italian earthquakes stronger than 2.0 magnitude on a Richter scale. During the whole seismic sequence it published 909 geolocalized tweets, both in the red and in the white zone (such tweets are not only related to the Emilia sequence, but report every earthquake stronger than 2.0 occurring in Italy). The first tweet by@INGVterremoti describing the May 20 shake appeared at 2:50 a.m. UTC, 47 minutes after the first shake, and it officially reports a $M_{L} 5.9$ earthquake localized in Modena Province.

Analyzing their profiles and the number of followers, following and tweets they have produced, the most active users in the 3 zones, with the exception of @INGVterremoti, tend to be "common" users. In the red zone, they have limited numbers of followers and tweets. In the white zone, even if they have average numbers of followers, they show a propensity to pro-

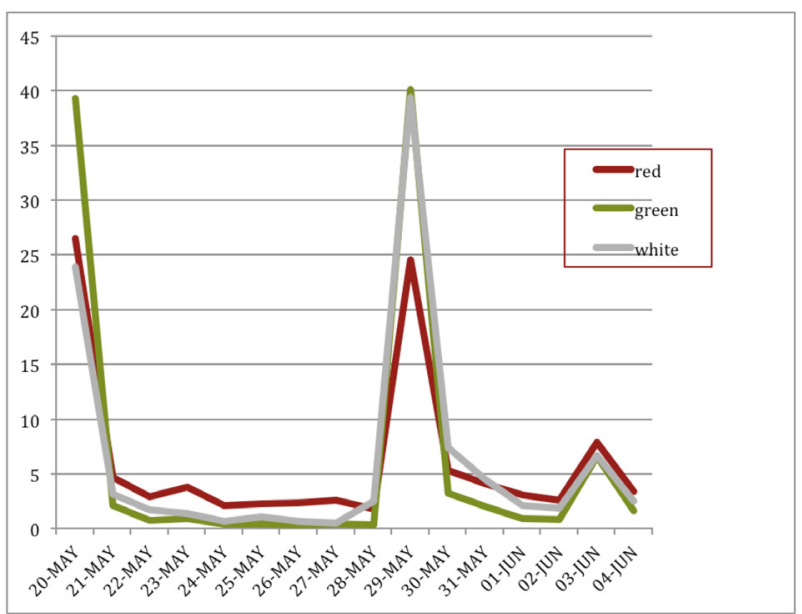

Figure 6. Number of tweets over time - percentage within single zone (whole database, in the 3 zones of Figure 1). 
ducing high amounts of tweets. A couple of journalists working in local newspapers appear among the most active users both in the red and in the green areas (in terms of Twitter metrics, they can nevertheless be defined as common users). By 'common' users we refer to accounts that are not institutional accounts (or media accounts), and that cannot be defined as Italian Twitter celebrieties. Our definition for Italian 'Twitter celebrities' in 2012 includes people with more than 25,000 followers at that date. Given the dimension of the Italian Twitter sphere, we consider this number as an indicator of celebrity. According to Social Bakers data (http:/ / www.socialbakers.com/twitter/country/italy/), moreover, the most followed 1000 Italian Twitter accounts had more than 25,000 followers. On Twitter celebrities see Romero and Kleinberg [2010], and Marwick and Boyd [2011]. We define as "quasi-Twitter celebrities" users with more than 15,000 followers.

Not surprisingly, users in the red zone appear generally more "engaged" with the topic. As Table 3 illustrates, they show: the lowest percentage of users only producing 1 tweet (although it's still a high rate: $\mathbf{4 5 . 0 8 \%}$ ); the highest mean number of tweet per user (4.2\%); a significant amount of users that are extremely active ( $8.2 \%$ of tweets produced by the four most active users). Moreover, in the red zone, even users that are scarcely active on the platform become highly active during the seismic sequence (showing how the relevance of the topic can influence users' standard Twitter behavior).

The most active users in the white zone, on the contrary, tend to generally have a highly active behaviour on Twitter. In the white zone, moreover, there is the highest percentage of "casual earthquake tweeters" (users producing only one tweet: $\mathbf{6 5 . 8 3 \%}$ ).

As Table 4 illustrates, the red zone shows the highest percentage of tweets containing hashtags, which are tools for organizing communication in a more topicoriented way. In the whole database, the use of hashtags appears much higher than the Italian average. The white zone shows the highest percentage of mentions and RTs. In this area people cannot share their direct experience, so they start sharing other people's direct experience or information by media and public figures.

Mention and retweet distributions describe different Twitter uses according to user location. Users in the red zone show less propensity to mentioning/retweeting $(18.83 \%$ of tweets) than users in the white zone $(32.09 \%)$. As the thematic categorization confirms (see below), two different Twitter functions emerge: Twitter as a direct witnessing tool vs Twitter as a second-hand information device. In the red zone, moreover, mentions are highly focused on a small amount of users, while in the white zone mentions are more dispersed (Table 3).

\begin{tabular}{|c|c|c|c|c|c|c|c|c|}
\hline & 3 zones & $\begin{array}{c}3 \text { zones } \\
\%\end{array}$ & Red & $\begin{array}{l}\text { Red } \\
\%\end{array}$ & Green & $\begin{array}{c}\text { Green } \\
\%\end{array}$ & White & $\begin{array}{c}\text { White } \\
\%\end{array}$ \\
\hline Number of users & $5318^{\mathrm{a}}$ & & $1007^{\mathrm{a}}$ & & $3553^{\mathrm{a}}$ & & $960^{\mathrm{a}}$ & \\
\hline Users producing only 1 tweet & 3316 & 62.35 & 454 & 45.08 & 2230 & 62.76 & 632 & 65.83 \\
\hline Tweets by most active userb & $169^{\mathrm{bc}}$ & $1.32^{\mathrm{bc}}$ & $162^{\mathrm{bc}}$ & $3.83^{\mathrm{bc}}$ & $66^{\mathrm{bc}}$ & $0.96^{\mathrm{bc}}$ & $31^{\mathrm{bc}}$ & $1.86^{\mathrm{bc}}$ \\
\hline$\%$ of tweets by 4 most active users & & $3.06^{\mathrm{b}}$ & & $8.32^{\mathrm{b}}$ & & $3.06^{\mathrm{b}}$ & & $5.39^{\mathrm{b}}$ \\
\hline Average Number of tweets by user & 2.40 & & 4.20 & & 1.94 & & 1.74 & \\
\hline
\end{tabular}

Table 3. The users. ( $\left.{ }^{(}\right)$Totals do not match, as some users have been localized in 2 different zones during the time span. ( $\left.{ }^{b}\right)$ As @INGVterremoti offers a professional information service (producing a disproportionately high amount of tweets), we have not included it here. ( ${ }^{c}$ ) The most active user in the entire dataset produced 169 tweets: among them, 162 in the red zone (this qualifies him as the most active user both in the 3 zones and in the red zone); the most active user in the green zone produced 66 tweets; the most active user in the white zone produced 31 tweets.

\begin{tabular}{lccccccc} 
& Red & $\begin{array}{c}\text { Red } \\
\%\end{array}$ & Green & $\begin{array}{c}\text { Green } \\
\%\end{array}$ & White & \multicolumn{2}{c}{$\begin{array}{c}\text { White } \\
\%\end{array}$} \\
\hline Reply to user & 444 & 10.5 & 987 & 14.34 & 328 & 19.68 & n.a. \\
\hline Mentions and RT & 796 & 18.83 & 1583 & 22.99 & 535 & 32.09 & $18(\mathrm{RT})$ \\
\hline Hashtag & 3585 & 84.81 & 4826 & 70.09 & 1046 & 62.75 & 23 \\
\hline URL & 592 & 14.01 & 583 & 8.47 & 215 & 12.9 & 18 \\
\hline
\end{tabular}

Table 4. Types of tweets tweeted in the 3 zones. $\left({ }^{\mathrm{a}}\right)$ Italian average, source (Spring 2012): Blogmeter. 
In each of the three zones, the most mentioned (and/or retweeted) users account for approximately $15 \%$ of all the mentions (see Table 5). As in previous studies [e.g. Murthy and Longwell 2013], our database lists user mentions and RTs together.

In the red zone we identified six top mentioned accounts: one institutional account; two media accounts; two "Twitter celebrities" and one user that can be listed as a "quasi-Twitter celebrity". In the green zone we identified 17 top mentioned accounts: one institution, eight media; five Twitter celebrities; two private companies (one of them, Groupalia, an online group buying company, strongly contested for trying to gain social media visibility through the hashtag) and one "quasi-Twitter celebrity". In the white zone among 19 top mentioned account we identified: one institution; four media; nine Twitter celebrities; two common users, one journalist (non-twitstar) and two private or currently removed accounts.

Only one institutional account (@INGVterremoti) appears among the most mentioned/retweeted accounts. In the green zone, there is a prevalence of media over Twitter celebrities, while in the white zone Twitter celebrities prevail on media. This can be related to the different levels of attention (and activation) people experience in the two zones. In the green zone, people are more likely to go and actively search for earthquakerelated information (following what can be defined a "pull" logic), therefore looking for information provided by news outlets (or at least following specific hashtags conversations, where media accounts appear to be highly active). In the white zone, people are less actively involved in looking for specific information, and are therefore more likely to receive information from accounts they are already following (therefore more diffusely relying - on average - on Twitter celebrities, following a "push" logic).

Even considering the whole database, institutional accounts (including public institutions, municipalities, civil protection, etc.) are almost never mentioned by users. At the same time, it is worth noticing that @INGVterremoti is the most mentioned account (130 total mentions). As shown by several tweets, Italian Twitter users show the need (and express their appreciation) for reliable and verified information, e.g "\#earthquake frankly I'm not sure whether to go to sleep or take out the dogs... We'd need an expert, don't we" (2:52:44, green zone, May 20).

Given that @INGVterremoti only provides a specific kind of earthquake information (earthquake's localization and magnitude), which is consistent with INGV's mission, users did not find on Twitter any other kind of information from authorities and public insti-

\begin{tabular}{lccc} 
& Red & Green & White \\
\hline Total mentioned users & 595 & 1293 & 486 \\
\hline Users mentioned only once & 453 & 1043 & 382 \\
\hline$\%$ users mentioned only once & 76.13 & 80.67 & 78.60 \\
\hline Total mentions & 1040 & 2006 & 678 \\
\hline $\begin{array}{l}\text { Mentions per user (mean) } \\
\text { Nr. of users that account }\end{array}$ & 1.75 & 1.55 & 1.40 \\
\begin{tabular}{l} 
for the $15 \%$ of whole mentions \\
\hline
\end{tabular} & 6 & 17 & 19 \\
\hline
\end{tabular}

Table 5. User mentions and retweet in the three zones of Figure 1.

tutions. Media, mainly mainstream (like newspapers or TV), and Twitter celebrities played a central role in the mention/RT process, exerting the influence that derives them from their structural position in the Twitter network. In fact, media accounts and Twitter celebrities somehow filled the void left by Italian institutions, in terms of first support, information about injured people or damages, practical instructions, etc.

The key element for understanding the role of Twitter celebrities, who are often pop-stars (singers, media anchor-men, etc.) with no specific competence in seismology or civil protection, is the network structure: these users are hubs within the Italian Twittersphere. At the time of the May 2012 Emilia earthquakes, and in many cases still now, institutional emergency managers and civil protection have a scarce presence on Twitter, at a local level, and even more so at a national level, in terms of active accounts and number of followers. Given their marginal presence, they were not exerting any relevant role in spreading reliable information; therefore, users were still getting a relevant part of their information from other users that are hubs in the Twitter network, mainly Twitter celebrities. During earthquakes, the role of such hubs is particularly high when users are far from the epicenter and show a weaker propensity to actively search for information sources.

2.4. First-hand information, locations and emotions: a deeper look at the first two hours after the major shakes

The first two hours after the two major shakes, respectively on May 20, 2012 (2:03 -4:02 a.m. UTC, 4:036:02 a.m. local time) and on May 29, 2012 (7:00-8:59 a.m. UTC, 9:00-10:59 a.m. local time), are particularly relevant, from a quantitative and a qualitative point of view. During the first two hours after the first shake of the seismic sequence (May 20, 2012) we collected 1857 tweets (almost $15 \%$ of the whole database); 1400 in the green zone, 408 in the red zone and 49 in the white zone. Figures 7 and 8 plot these tweets on a map: during the first two hours after the second most intense shake (May 29, 2012) the distribution is similar to the previ- 


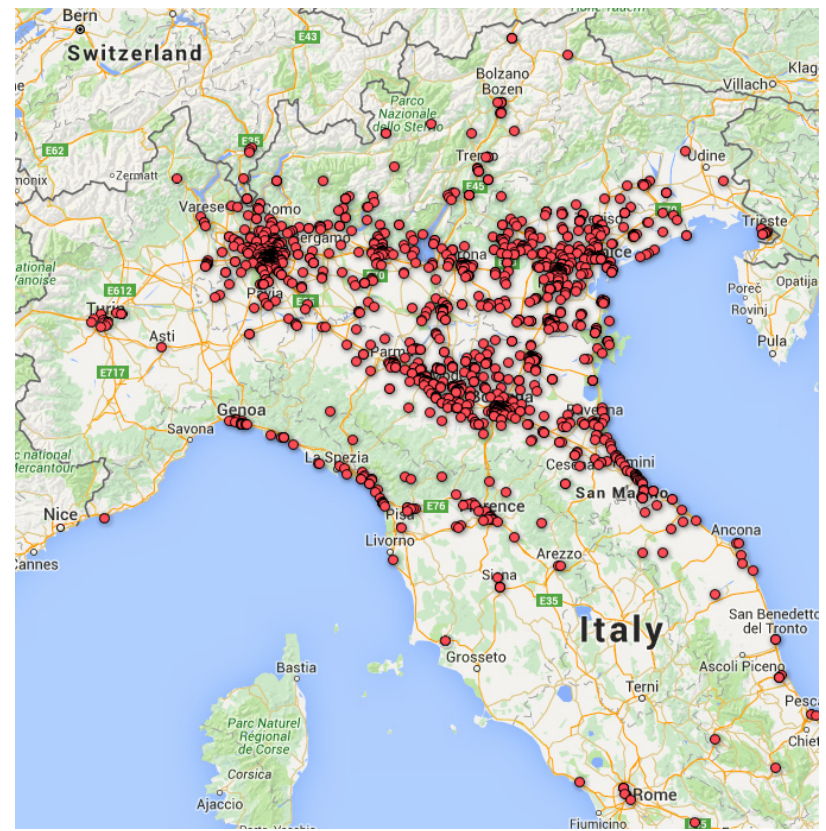

Figure 7. Tweets localization map: May 20, 2012, 2:00 a.m.-3:59 a.m UTC (Google Fusion Table).

ous one. There were 1916 tweets: 1428 in the green zone, 325 in the red zone and 163 in the white zone.

Adopting a grounded method [Glaser and Strauss 1998], we manually analysed (close reading; Brummett [2010]) the tweets written in the first two hours after the first two major (May 20, 2:03 UTC; May 29, 7:00 UTC) shakes and we identified 12 categories (Table 6). The stated categories partially differ from the taxon-

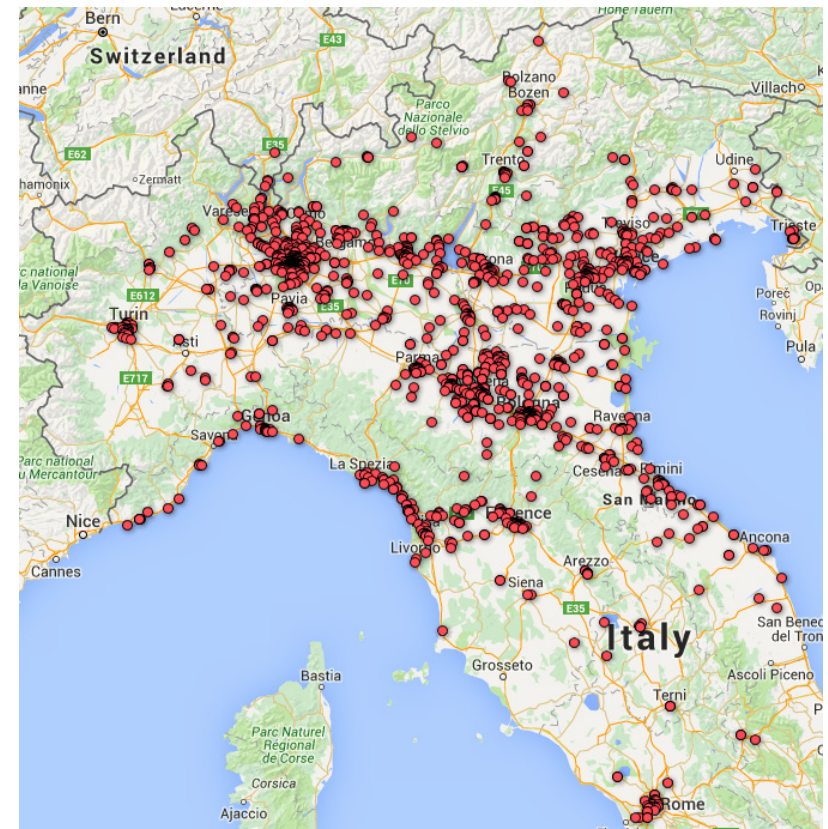

Figure 8. Tweets localization map: May 29, 2012, 7:00 a.m.- 8:59 a.m. UTC (Google Fusion Table).

omy proposed by Bruns et al. [2012]. The authors proposed a categorization that explores the uses of Twitter during a natural disaster, identifying five macro-categories: Information, Media Sharing, Help and Fundraising, Direct Experience, Reaction and Discussion. Our taxonomy mainly focuses on users' communicative needs and practices, in order to describe the motivations for using Twitter immediately after an earthquake

\begin{tabular}{|c|c|}
\hline Category & Definition \\
\hline First hand information & Tweets including a first-hand report concerning the event. \\
\hline Location & $\begin{array}{l}\text { Tweets making reference to specific places in addition to automatic geolocalization (i.e. where the user is lo- } \\
\text { cated or where the event takes place). }\end{array}$ \\
\hline Emotive & Tweets describing the user mood and her/his emotive reaction (e.g. fear, surprise, irritability, etc.). \\
\hline Effect description & Tweets describing the effect of the event (damages, injured or dead people, etc.). \\
\hline Routine interruption & Tweets describing the interruption of the everyday user activities (e.g. sleeping, going to school, commuting). \\
\hline Second hand information & Tweets reporting second-hand information concerning the event (from media, other users, public institution etc.). \\
\hline Comments & $\begin{array}{l}\text { Tweets reporting general comments on the event, such as: the role and inefficiency of mass media; polemics } \\
\text { against political institutions; expression of solidarity toward victims; other personal reactions. }\end{array}$ \\
\hline Irony & Tweets composed by jokes, ironic stories and funny anecdote that took place during the event. \\
\hline Information request & $\begin{array}{l}\text { Tweet asking for information about the magnitude of the earthquake, number of victims, emergency guide- } \\
\text { lines to follow. }\end{array}$ \\
\hline Useful information & $\begin{array}{l}\text { Tweet providing useful and practical information about the event (e.g. services issues, useful telephone num- } \\
\text { bers, public transportation delays, request to open the Wi-Fi networks). }\end{array}$ \\
\hline Meta social media & Tweets reporting comments on the role of social media in crisis response. \\
\hline Other & ther kind of tweets \\
\hline
\end{tabular}

Table 6. Categories of the tweets written in the two hours after the first two major shakes (occurred on May 20, 2012, 2:03:52 a.m. - 3:59 a.m. UTC, and on May 29, 2012, $7.00-8.59)$. 
(and therefore our categories and results differ from analyses related to longer periods of time). The final aim is to describe how users' communicative needs vary according to their spatial localization. Our categories are neither exhaustive nor mutually exclusive; nevertheless, they give useful insights on the communication patterns taking place immediately after the shake, with particular regard to content and to style. The use of the different categories of tweets is discussed below. The analysis has been carried out by two of the authors; in order to gain intercoder reliability, $25 \%$ of the tweets have been analyzed jointly by the two authors, before proceeding to individual analysis; subsequently, authors have largely discussed tweets whose attribution appeared problematic. In order to focus our analysis only on those places where the earthquake has been clearly perceived, we did not analyze tweets coming from the white area. Most of the tweets are written in Italian: in order to make the text understandable, we provided an English translation.

The tweet categories distribution follows the same patterns after the first two major shakes of the seismic sequence (May 20 and 29, 2012): we observe a prevalence of tweets reporting first hand information together with the localization of the user or the expression of his/her feelings. Most of the users use Twitter in order to immediately report that they felt an earthquake: "Very strong earthquake in Castel Maggiore!!" (2:24:54, red zone, May 20).

Tweets providing first-hand information $(63.3 \%$ red zone; $69.1 \%$ green zone). Most of the users, especially in the very first minutes, simply use Twitter to claim that there has been a shake: "earthquake". Personal and direct experience is briefly reported. Sometimes, the simple use of punctuation is used to underline the relevance of the shake, but also the emotive reaction of the user: "earthquake!!!!!!!!” (2:05:43, red zone, May 20).

Tweets referring to geographical locations $(43.8 \%$ red zone; $34.9 \%$ green zone). A relevant part of the tweets reports the localization of the user or, after the first information is shared, the localization of the epicentre, such as: "earthquake in Bologna".

Tweets expressing emotions (29.6\% red zone; $27.1 \%$ green zone). Many users share their emotions (mainly fear, surprise, anxiety, sometimes anger): "Oh my God the earthquake! A very strong shake. Panic" (2:06:23, green zone, May 20); "I cried out of fear \#earthquake" (7:32, red zone, May 29). After the second big shake, users say they "can't stand it anymore": "Other shakes?!! I can't stand it \#earthquake" (3:57:19, red zone, May 20). Many of the emotive tweets also include first hand information.
Tweets describing the effects of the shakes $(24.4 \%$ red zone; $16.6 \%$ green zone). Some tweets provide useful first hand information in order to get some hints about the damage produced by the earthquake according to the users' localization. For example, the movements of objects and furniture and the shake intensity perception (e.g. the user felt or did not feel the shake, the user woke up during the shake). "Very strong shake in Ferrara; furniture on the ground and the house is still shaking" (2:30:48, red zone, May 20). Some users report the building damages and/or first hand information about injured citizens. For example: "Serious situation \#earthquake San Felice Mirandola Cavezzo: collapses and trapped victims" (8:15, green zone, May 29). All these user-generated tweets offer practical information in order to better understand the consequences of the shake(s).

Tweets providing second-hand information $(16.1 \%$ red zone; $10.4 \%$ green zone). Some tweets report second-hand information concerning the event in order to extend the reach and visibility of that tweet. For example some users generally retweet news from media outlets and directly link to an online source (a map, an online news). Some other users simply retweet information generated by other users, e.g. “RT @24emilia: Attention: Cavezzo immediately needs first aid. Urgent \#earthquake \#Modena" (8:42, green zone, May 29); several RT of the @INGVterremoti account; retweet of news from media outlets: "I'm watching skytg24, there are some victims of the earthquake...Shit..." (8:20, green zone, May 29).

Ironic tweets (12.7\% red zone; $8 \%$ green zone). Irony is a widespread communication style on Twitter; even during a dramatic event such as an earthquake, some users tend to write ironic tweets (unsurprisingly, ironic tweets are less than in other contexts, but they still constitute more than the $12 \%$ of the database in the red zone). Some people ironically say they thought it wasn't an earthquake, but the girlfriend moving in the bed, their hangover, the food they have eaten, their roommates etc. Others ironically "thank" the earthquake for the wakeup without any alarm clock. Some others ironically mention the "Maya prophecy" that predicted the end of the world by the end of 2012.

Tweets referring to routine interruption $(11 \%$ red zone; $13.9 \%$ green zone). Many tweets report what users were doing when they felt the shake, a sort of micro autobiographical storytelling in real time. It is well known that people accurately remember the activity they were carrying out when a dramatic event or a crisis occurred; Brown and Kulik [1977] called these snapshots "Flashbulb memory". Therefore the tweets contain a wide collection of users' memories regarding 
their personal experience of the event. "So I was the only one not sleeping, caring for my daughter?" (3:18:17, green zone, May 20). Other users describe what they are doing immediately after the shake, or their attempt to restore their normality: "Solara. Everybody is on the street because of the \#earthquake. What a wake-up!" (2:53:14, red zone, May 20). Tweets related to "sleeping" are especially frequent in the green zone, after the first shake: there are users saying they have been woken up by the quake, while others express their willingness to fall asleep again.

Tweets providing comments about the shake (or related topics, such as media coverage, institutional reactions, etc.) (6.5\% red zone; $10.3 \%$ green zone). Users express several kinds of reaction to the event. Some citizens use Twitter to comment on the role of mass media during the emergency, mainly to underline that media are not providing useful and timely information (e.g. "What a media ecosystem in Italy! And we deserve it \#earthquake" - 7:50, red zone, May 29), or that they are superficially covering the news: "Just heard at tg2: let's talk about the other earthquake that shook the football game \#fuck" (8:45, green zone, May 29). Some citizens, after the May 29 shake, argue that politicians and institutions are not effectively reacting to the emergency. Only few people use Twitter to express solidarity toward victims and injured people.

Tweets requesting information $(4.9 \%$ red zone; $7.9 \%$ green zone). Some citizens use Twitter to ask information about the earthquake. During the first minutes after the shake several users, especially from the green zone, use Twitter to ask other users if they perceived the earthquake, looking for any kind of information that can confirm their sensations: "\#Earthquake I'm in Prato, can you confirm it?" (7:02, green zone, May 29). With the passing of time Twitter is used to publicly ask for: the magnitude of the earthquake; where the epicenter is; to verify word-of-mouth reports and to know what is going on in specific cities and villages; to get emergency guidelines to follow; to directly ask their friends if they are OK (“@ElisaManna Are you here? Is everything OK? Did you hear the \#earthquake?" -2:22, red zone, May 20).

Tweets related to the role of social media in the aftermath of the shakes (metacommunication about social media) (2.4\% red zone; $3.1 \%$ green zone). Some tweets comment on the role of social media during emergencies. Some users underline that Twitter is faster and more reliable than traditional media: "Facebook better than Skytg24" (2:59, green zone, May 20); "Thank you Twitter for existing. In such dramatic moments like this \#earthquake I appreciate social networks even more, they're better than TV or newspapers"
(3:48, green zone, May 20). Some others underline the ironic side of such Twitter usage: "Ahah instead of going under a table, people, including me, have gone online" (2:41, red zone, May 20).

Tweets providing useful information $(0.2 \%$ red zone; $0.9 \%$ green zone). It is a residual category. We found almost no tweet providing useful and practical information about the event (e.g. services issues, useful telephone numbers, public transportation delays, emergency guidelines). Most of that information has been directly created by the users: therefore, users' conversation report the absence of official communication produced by public institutions.

As Figure 9 shows, both the green and the red zone show a prevalence of "first-hand information" tweets; more specifically, the green zone has a stronger prevalence of "first-hand information" tweets, while in the red zone the role of "location tweets" and tweets describing the effect of the shakes is more relevant than in the green zone. The share of "second hand information" tweets is higher in the red zone, confirming the need of those citizens to find information about the event; while in the green zone there is a greater share of "routine interruption", tweets describing what users were doing when they felt the shake and how it affected their daily routines.

The prevalence of first hand tweets (often combined with localization information and the description of the effects of the shake) shows that users are first of all willing to share first hand information, almost in real time. As Boccia Artieri et al. [2012] observed, during the very first minutes after the first shake of the Emilia sequence, a "witnessing" function prevails (mainly descriptive, but also emotive). In the following minutes and hours, people also turn to Twitter to look for information, sometimes directly asking for it. Several research projects are creating specific algorithms in order to automatically extract information from location-based tweets in order to detect on-going events. Sakaki et al. [2010] created a system to detect an earthquake in Japan by observing tweets in real time, in order to promptly send email alerts to target population. Our research shows that $24.4 \%$ (red zone) and $16.6 \%$ (green zone) of the analysed geolocalized tweets convey specific information about the effect of the shakes. Further research should also take into consideration other studies that analyse the use of web mapping platforms in order to investigate the contribution that location based tweets can offer to better describe the effect of an earthquake.

Our analysis also describes how citizens use Twitter as a tool for sharing emotions and for creating a sense of community. Especially during the first minutes after the first shake (that occurred during the night) the 


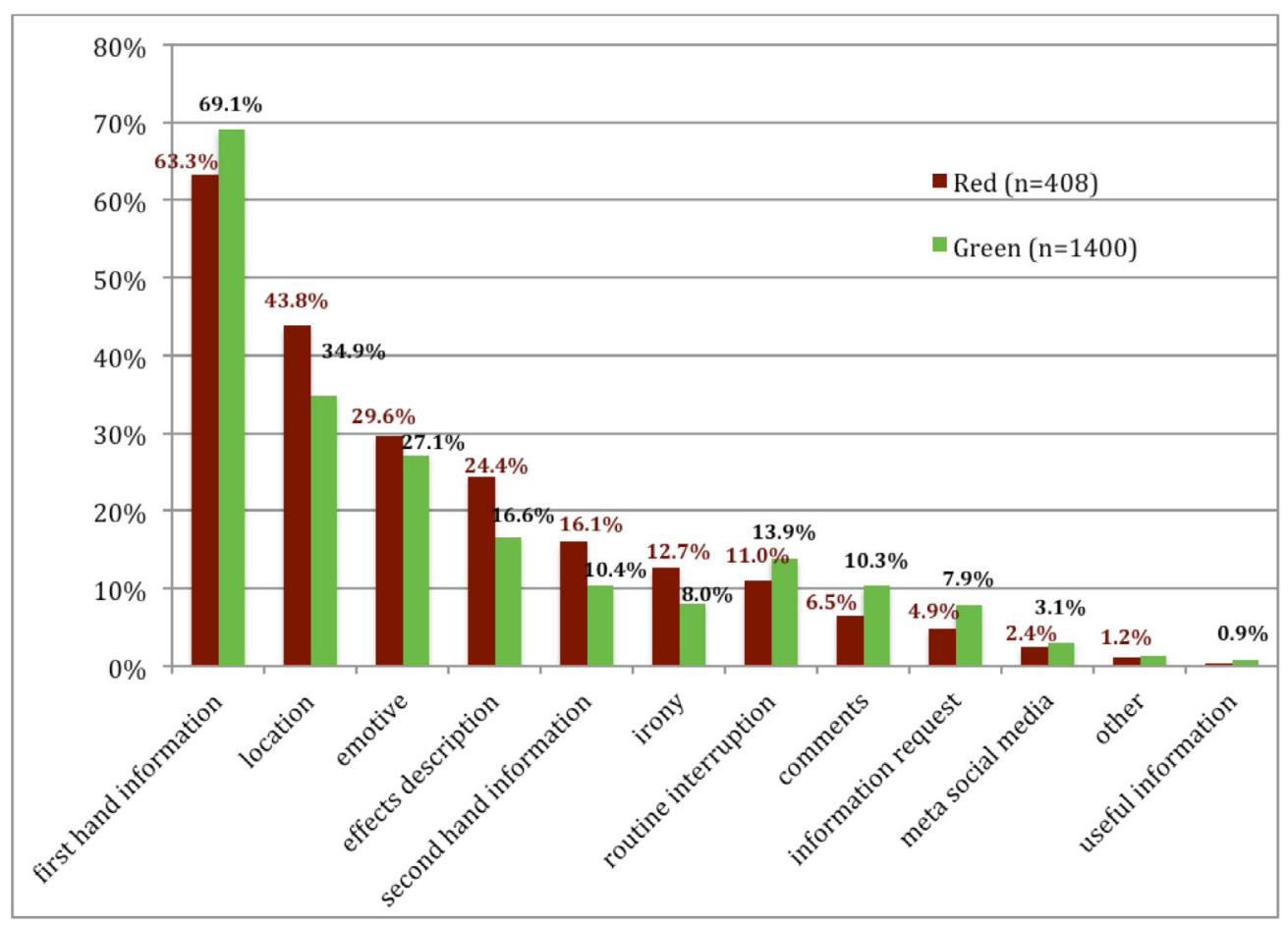

Figure 9. Tweet content categories according to tweets localization (May 20, 2012, 2:03 a.m. - 4:02 a.m. UTC).

presence of other users online seems to provide a sort of emotional support: "Thanks \#Twitter we are a few people but you support me. Let's try to sleep, now the \#earthquake frights me less" (2:49, green zone, May 20). At the same time the relevant number of ironic tweets written in the first two hours after the two most intense shakes seem to represent a sort of unconscious collective reaction to the earthquake, a way to publicly express the need to understate this dramatic event.

\section{Discussion, conclusions, and future research}

The paper analysed the geolocalized tweets generated during the Emilia 2012 seismic sequence in order to understand if the distance from the epicentre activates different Twitter uses (i.e. patterns of information sharing, most active users, top mentioned accounts) reflecting different users' needs and behaviours.

The analysis confirms that Twitter's orientation towards real-time, or quasi real-time, communication might represent a relevant resource for earthquake situations; it is mainly used for communicating immediately after having felt the shake (or having had the news). In the first two hours we observed a strong witnessing function, both descriptive and emotional. Users put into practice different engagement rates according to their geographic location: in the red zone, for example, where the experienced intensity of the shake was highest, the earthquake topic affects the daily Twitter use.

According to Jung [2012], during acute events users look for reliable and timely information on Twitter. Given the Twitter network structure, information produced by hubs (accounts that have high visibility) is more likely to exert a relevant influence within a specific network, and to effectively communicate in emergency contexts. The results show that during the May 2012 Emilia earthquakes media accounts and Twitter celebrities have somehow filled the void left by institutions within the Italian Twitter sphere. Indeed most of the Italian public institutions still have to achieve an authoritative role on Twitter, a role that is crucial to effectively spread the circulation of useful and verified information and to limit the circulation of rumors and hoaxes that tend to emerge in emergency context. Actually, due to the above mentioned Twitter network structure, Italian institutions that used social media accounts during a natural disaster [Parisi et al. 2014] appeared far less influential than other Twitter users (e.g. local Twitter celebrities) also because the majority of institutional accounts have relatively small numbers of followers. Therefore, it is crucial to plan communication campaigns to increase institutional accounts visibility during rest periods, in order for them to become a hub before a natural disaster occurs.

Moreover, we strongly recommend that during rest periods citizens should be trained to better understand and handle emergency situations, providing accurate and effective scientific communication, including communication of uncertainty and risk.

We are aware that our database of only geolocalized tweets constitutes a very small sample of the whole Twitter activity (as discussed above, it represents about $2.4 \%$ of the whole Twitter activity). In fact, the specific 
nature of such a sub-sample can introduce biases in the analysis: first, in relation to tweet distribution over time; second, in relation to the characteristics of the sub-sample of users that enable geolocalization on their mobile phones. Comparisons between full datasets and geolocalized ones should be carried out in the future, in order to better address such biases, which should be taken into account when designing systems deploying user-generated social media information for disaster analysis and management purposes. We believe that the growing interest, both by hard scientists and social scientists, in such systems (see, for instance, Earle et al. [2010], MacEachren et al. [2011], Taylor et al. [2014]) justifies such a focus.

Moreover, we hope that our results 1) can contribute to our understanding of online disaster communication processes, and 2) can be usefully employed as a background for designing and managing information services during emergencies and natural disasters. Furthermore, transnational comparisons are also needed, in order to better understand the peculiarities of the Italian context. Our understanding of such dynamics, moreover, will surely benefit from an analytical consideration of the digital media ecosystem (including all the communication platforms people use in order to interact and to produce content related to a specific event). A broader understanding of the role of digital communication in handling natural hazards should surely consider a longer temporal perspective. It should include not only the use of social media during the emergency and in the next few days but also its use in rest periods.

Our research project is still on-going. We hope that our multidisciplinary research can contribute to effectively designing crisis communication strategies on social media according to users needs and behaviours. Moreover we hope that such results can be usefully employed for managing information services during emergencies and natural disasters.

\section{References}

Avvenuti, M., M.G.C.A. Cimino, S. Cresci, A. Marchetti and M. Tesconi (2016). A framework for detecting unfolding emergencies using humans as sensors, SpringerPlus, 5, 43; doi:10.1186/s40064-016-1674-y.

Boccia Artieri, G., F. Giglietto and L. Rossi (2012). \#terremoto! l'uso di Twitter durante il terremoto tra testimonianza, propagazione e commenti. Retrieved from http://goo.gl/9UsusQ (in Italian).

Brown, R., and J. Kulik (1977). Flashbulb Memories, Cognition, 5 (1), 73-99.

Brummett, B. (2010). Techniques of Close Reading, London, Sage.

Bruns, A., J.E. Burgess, K. Crawford and F. Shaw (2012).
\# qldfloods and@, QPSMedia: Crisis communication on Twitter in the 2011 south east Queensland floods, Report of the Centre of Excellence for Creative Industies and Innovation, Brisbane, ARC. Retrieved from http: / / www.cci.edu.au/ floodsreport.pdf.

Bruns, A., and H. Moe (2014). Structural Layers of Communication on Twitter, In: K. Weller, A. Bruns, J. Burgess, M. Mahrt and C. Puschmann (eds.), Twitter and Society, Peter Lang, New York, 15-28.

Bruns, A., and S. Stieglitz (2014). Metrics for understanding communication on Twitter, In: K. Weller, A. Bruns, J. Burgess, M. Mahrt and C. Puschmann (eds.), Twitter and Society, Peter Lang, New York.

Cha, M., H. Haddadi, F. Benvenuto and K. Gummadi (2010) Measuring User Influence in Twitter: The Million Follower Fallacy, ICWSM, 10 (10-17), 30.

Coombs, W.T., and S.J. Holladay, eds. (2010). The Handbook of Crisis Communication, Chicester, Wiley-Blackwell.

Cooper, G.P., V. Yeager, F.M. Burkle and I. Subbarao (2015). Twitter as a Potential Disaster Risk Reduction Tool, Part I, Part II, Part III and Part IV, Plos Currents, 7.

Earle, P., M. Guy, R. Buckmaster, C. Ostrum, S. Horvath and A. Vaughan (2010). OMG earthquake! Can Twitter improve earthquake response?, Seismological Research Letters, 81 (2), 246-251; doi:10.1785/ gssrl.81.2.246.

Fraustino, J.D., B. Liu and Y. Jin (2012). Social media use during disasters: A review of the knowledge base and gaps, Report of the National Consortium for the Study of Terrorism and Responses to Terrorism. Retrieved from http://goo.gl/0EeUWM.

Gaffney, D., and C. Puschmann (2014). Data Collection on Twitter; In: K. Weller, A. Bruns, J. Burgess, M. Mahrt and C. Puschmann (eds.), Twitter and Society, Peter Lang, New York, 55-67.

Giacobe, N.A., and P.J. Soule (2014). Social Media for the Emergency Manager in Disaster Planning and Response, In: Proceedings of the 11th International ISCRAM Conference, University Park, PA, USA.

Glaser, B.G., and A.L. Strauss (1998). Grounded theory, Strategien qualitativer Forschung, Bern, 53-84.

Hughes, A., L.A. St. Denis, L. Palen and K.M. Anderson (2014a). Online Public Communication by Police and Fire Services during the 2012 Hurricane Sandy, In: Proceedings of CHI 2014, Toronto, ON, Canada.

Hughes, A., L. Palen and S. Peterson (2014b). Social Media and Emergency Management, In: J.E. Trainor and T. Subbio (eds.), Critical Issues in Disaster Science and Management: A Dialogue Between Researchers and Practitioners, Emmitsburg, MD, FEMA 
Higher Education Project.

ISTAT (2015). GeoDemo, January 2015. Retrieved from http:/ / demo.istat.it/pop2015/index.html.

Jung, J.Y. (2012). Social media use and goals after the Great East Japan Earthquake. First Monday, 17 (8). Retrieved from http:/ / goo.gl/ 7mZ2Sy; doi:http:/ / dx.doi.org/10.5210/fm.v17i8.4071.

Leetaru, K.H., S. Wang, G. Cao, A. Padmanabhan and E. Shook (2013). Mapping the global Twitter heartbeat: The geography of Twitter, First Monday, 18 (5/6). Retrieved from http:/ / goo.gl/yiGfVZ; doi: http:/ / dx.doi.org/10.5210/fm.v18i5.4366.

MacEachren, A.M., A.C. Robinson, A. Jaiswal, S. Pezanowski, A. Savelyev, J. Blanford and P. Mitra (2011). Geo-Twitter Analytics: Applications in Crisis Management, In: Proceedings of 25th International Cartographic Conference, France. Retrieved from http:/ / goo.gl/yvI5Y8.

Marwick, A., and D. Boyd (2011). To see and be seen: Celebrity practice on Twitter, Convergence: The International Journal of Research into New Media Technologies, 17 (2), 139-158; doi:10.1177/ 13548565 10394539.

Morstatter, F., J. Pfeffer, H. Liu and K.M. Carley (2013). Is the Sample Good Enough? Comparing Data from Twitter's Streaming API with Twitter's Firehose, arXiv preprint arXiv:1306.5204.

Muralidharan, S., L. Rasmussen, D. Patterson and J. Shin (2011). Hope for Haiti: an analysis of Facebook and Twitter usage during the earthquake relief efforts, Public Relations Review, 37 (2), 175-177.

Murthym, D., and S.A. Longwell (2013). Twitter and disasters. The uses of Twitter during the 2010 Pakistan floods, Information, Communication and Society, 16 (6), 837-855; doi:10.1080/1369118X.2012. 696123.

Parisi, L., F. Comunello and A. Amico (2014). \#allertameteoSAR: analisi di un hashtag di servizio tra dinamiche di influenza e nuove forme di engagement, In: F. Comunello (ed.), Social media e comunicazione d'emergenza, Guerini, Milano, 121-140.

Plotnick, L., S.R. Hiltz, J.A. Kushma and A. Tapia (2015) Red Tape: Attitudes and Issues Related to Use of Social Media by US County-Level Emergency Managers, In: Palen, Büscher, Comes and Hughes (eds.), Proceedings of the ISCRAM 2015 Conference - Kristiansand, May 24-27.

Potts, L. (2013). Social media in disaster response: How experience architects can build for participation, New York, NY, Routledge.

Rodriguez, H., E.L. Quarantelli and R.R. Dynes, eds. (2007). Handbook of Disaster Research, New York, NY, Springer.
Romero, D. M., and Kleinberg, J. M. (2010). The directed closure process in hybrid social-information networks, with an analysis of link formation on Twitter. Proceedings of the Fourth International AAAI Conference on Weblogs and Social Media, 138-145.

Sakaki, T., M. Okazaki and Y. Matsuo (2010). Earthquake shakes Twitter users: real-time event detection by social sensors, In: Proceedings of the 19th international conference on World wide web, 851-860.

Starbird, K., and L. Palen (2010). Pass It On?: Retweeting in Mass Emergency, In: Proceedings of the 7th International ISCRAM Conference, USA. Retrieved from http:/ / idl.iscram.org/files/starbird/2010/970 Starbird+Palen2010.pdf.

Starbird, K., and L. Palen (2011). 'Voluntweeters': SelfOrganizing by Digital Volunteers in Times of Crisis, In: Proceedings of CHI 2011, Vancouver, Canada.

Taylor, S., A. Poorthuis, M. Graham and M. Zook (2014). Mapping the data shadows of Hurricane Sandy: Uncovering the sociospatial dimensions of Big Data, Geoforum, 52, 167-179; doi:10.1016/j.geoforum.20 14.01.006.

Tosi, P., P. Sbarra, V. De Rubeis and C. Ferrari (2015), Macroseismic intensity assessment method for webquestionnaires, Seismological Research Letters, 86, 985-990; doi:10.1785/0220140229.

White, J.I., L. Palen and K.M. Anderson (2014). Digital Mobilization in Disaster Response: The Work and Self-Organization of On-Line Pet Advocates in Response to Hurricane Sandy, In: Proceedings of CSCW'14, Baltimore, MD, USA.

Wilken, R. (2014). Twitter and Geographical Location, In: K. Weller, A. Bruns, J. Burgess, M. Mahrt and C. Puschmann (eds.), Twitter and Society, Peter Lang, New York, 155-167.

\footnotetext{
${ }^{\star}$ Corresponding author: Francesca Comunello, Università di Roma LUMSA, Rome, Italy; email: f.comunello@lumsa.it.
}

C 2016 by the Istituto Nazionale di Geofisica e Vulcanologia. All rights reserved. 